Open Access

\title{
Impact of farmer education on farm productivity under varying technologies: case of paddy growers in India
}

Kirtti Ranjan Paltasingh ${ }^{1 *}$ and Phanindra Goyari ${ }^{2}$

\author{
* Correspondence: kirtti.paltasingh@ \\ gmail.com \\ ${ }^{1}$ School of Economics, SMVD \\ University, Jammu 182 320, India \\ Full list of author information is \\ available at the end of the article
}

\begin{abstract}
This paper analyzes the effects of education on farm productivity in the case of growers of modern and traditional varieties of paddy in Odisha, Eastern India. Using an endogenous switching regression model, the study has found that a minimum threshold level of education is significantly influencing the adoption of modern varieties of paddy and thereby the farm productivity of adopters only. So, the study finds the evidence in support of Schultz hypothesis that says education enhances farm productivity in the case of adopters of modern technology. The study suggests that farmers' field school program must be implemented along with a strong extension network in the study region for a wider dissemination modern technology.
\end{abstract}

Keywords: Education, Technology adoption, Farm productivity, Endogenous switching regression

JEL classification: Q12, Q16, C31

\section{Background}

After the seminal work of Schultz (1964), the importance of education in agricultural development has been widely affirmed. Education enhances the farming skills and productive capabilities of the farmers (Weir 1999). It enables them to follow some written instructions about the application of adequate and recommended doses of chemical and other inputs (Appleton and Balihuta 1996; Huang and Luh 2009). Again, numeracy helps them to calculate the costs and benefits of adopting a particular farming technology. But, the empirical assessment of that hypothesis has remained inconclusive (Asadullah and Rahman 2009; Hojo 2004; Lockheed et al. 1980; Narayanmoorthy 2000). No consensus has so far been agreed upon among the experts who studied the impact of farmer education on farm productivity. A group of studies (e.g., Abdulai and Huffman 2014; Asadullah and Rahman 2009; Azhar 1991; Chaudhri 1979; Duraisamy 1992; Mellor 1976; Pudasaini 1983; Ram 1980; Singh 1974; Young and Deng 1999) found a significant role of education in augmentation of agricultural productivity. On the other hand, studies like Battese and Coelli (1995), Coelli et al. (2002), Deb (1995), Kalirajan and Shand (1985), Llewellyn and Williams (1996), Narayanamoorthy (2000), and Wadud and White (2000) did not find any significant impact of education on farm 
productivity and efficiency. Some studies (e.g., Hasnah and Coelli 2004) found even a significant negative impact of education on farm efficiency. Again, studies like Lockheed et al. (1980), Phillips (1994), and Tilak (1993) reported mixed results. ${ }^{1}$

The possible reasons for the inconclusive empirical results of the impact of education on agricultural productivity arise mainly due to four issues-(i) how to quantify the variable "education", (ii) whose education needs to be taken into account, (iii) where it matters, and (iv) whom it matters to? The former two issues are related to the construction of the variable "education" used in empirical models. The latter two issues are concerned with the importance of formal education in varying farm environments and also to different farmers in the same environment. The first two issues are discussed at length and breadth by Lockheed et al. (1980) and Phillips (1994). On the question of how should education be measured, many authors took years of schooling attained or completed (Asadullah and Rahman 2009; Asfaw and Admassie 2004; Chaudhri 1979; Hojo 2004; Jamison and Lau 1982; Narayanamoorthy 2000; Reimers and Klasen 2013; Rahman et al. 2012), but some authors used the dummy variable showing attainment of a threshold level of certain years of schooling (Hojo 2004; Huang and Luh 2009; Jamison and Moock 1984; Moock 1973). ${ }^{2}$ Again, the number of grades attended was also taken in studies like Haller (1972) or sometimes a simple indicator of literacy (Sharma 1974). Coming to the question of "whose education matters" in agricultural development, we find different studies taking education of different persons like education of the head of the farming household, average education of the household, maximum education of any member of the household, and minimum level of education of any household member above 14 years of age. ${ }^{3}$ These two issues are well taken up in many studies (see Alene and Manyong 2007; Asadullah and Rahman 2009; Hojo 2004) as they incorporated more than one measure of education in the empirical model that covers both household head's education as well as the education level of other members. Again, in those studies, education is defined as years of schooling or a dummy variable showing a minimum threshold level.

The third important reason is ascribed to the wrong assumption of a homogeneous farming environment that all farmers operate in. Schultz (1975) argued that education plays a significant role in modernized farm environment rather than the traditional one. The ability to deal with the disequilibria caused by the adoption of modern technology is largely a function of farmer's education. Thus, more educated farmers adjust better and quicker than the less educated or illiterate farmers (Ali and Byerlee 1991; Hojo 2004). However, most of the past studies assumed that farmers operate in a uniform farm environment. So, the effects of conventional and non-conventional inputs on farm productivity are independent of the type of farm environments (Appleton and Balihuta 1996; Jamison and Moock 1984; Moock 1981). This again leads to another issue (that is, the fourth concern) that even in the same farm environment, as argued by Alene and Manyong (2007), farmers are not exposed to a homogeneous technology. Some farmers are adopters of modern technology while others are not. In their study, they found a significant impact of farmer education on adoption decision of modern cowpea varieties and thereby on-farm productivity of adopters in Nigeria. Thus, as they argue "the failure to account for differences in technology available to farmers, even in the same farm environment, is likely to confound the true effects of education on agricultural productivity" (Alene and Manyong 2007, p.156). So, the empirical specifications and subsequent analyses without taking care 
of all these issues fully may provide incomprehensible and confounding results. Hence, many studies found insignificant or even negative impact of education on agricultural productivity.

Coming to Indian agriculture, there is a dearth of research on this particular issue. Very few studies have been conducted on the present issue, and there is a lack of consistent and concrete evidence of a significant positive relationship between farmer education and farm productivity. Most of the studies suffer from the methodological deficiencies discussed above. Moreover, none of them tried to test the Schultz hypothesis (Schultz 1975) by taking care of the issues of differences in farming environments and technologies available to different groups of farmers within the same environment. ${ }^{4}$ Among the available studies in India, only Narayanamoorthy (2000) analyzed the impact of education on farm productivity in the case of two high yielding paddy varieties (CR1009 and ADT 36) by taking average household education in terms of years of schooling, but the results were insignificant. ${ }^{5}$ This illustrates the need for further investigation on the topic after taking care of all the methodological issues discussed above. Therefore, the present study sets out to examine the impact of farmer education on farm productivity in the case of modern and traditional paddy growers in Odisha, a major rice-producing state in Eastern India. More specifically, the study aims at testing the Schultz hypothesis and also try to find out which specification of education variable is a better measure to delineate the impact of education on farm productivity. Following Alene and Manyong (2007), Asfaw et al. (2012), Di Falco et al. (2011), and Khonje et al. (2015), an efficient version of endogenous switching regression model is used, after controlling for different exogenous factors and other farm and farmers' characteristics, to test the differential impact of education on farm productivity under both technologies. Only the paddy growers are taken as a case study since paddy is the major crop and staple food for the state of Odisha.

The paper is organized in the following manner. After a brief background in the "Background" section, the "Methods" section provides an outline of the analytical framework and also describes the study area, data collection, and empirical model specification with emphasis on the hypothesized relations. The "Results and discussion" section presents the empirical results, their analysis, and discussion. The "Conclusion" section concludes with some policy implications.

\section{Materials and methods}

Endogenous switching regression is a suitable method to analyze the core objective of the paper, namely, the impact of farmer education on farm productivity, given the technology adoption status. This method takes care of two econometric problems-endogeneity and sample selection bias. The analysis of the impact of technology adoption on productivity and other welfare outcomes poses a problem of possible endogeneity (Asfaw et al. 2012; Hausman 1978) because there is likely to be a two-way relationship between technology adoption and productivity enhancement (Alene and Manyong 2007). First, technology adoption may cause productivity enhancement for some farmers. However, at the same time, enhanced productivity also induces more technology adoption. Thus, adoption decision is either voluntary, or some technologies are targeted to a group of farmers. Farmers, who are more productive, adopt more technologies because of their self-decision. This 
self-selection decision into technology intervention is a potential source of endogeneity, and it results in an overstatement of the true impact of technology on productivity if not accounted for properly. Again, the less productive farmers are also encouraged to adopt technology because of its productivity enhancement capabilities. This, if not accounted for properly, will result in an understatement of the true impact of technology adoption on productivity. Therefore, the productivity outcome between the adopters of modern technology and non-adopters could be due to unobserved heterogeneity caused by innate abilities and other unobserved farmers and farm-specific characteristics. This leads to inconsistent estimates of the impact of technology adoption. Because of this difference in initial conditions between adopters and nonadopters caused by unobserved farm and farmer characteristics being only known to farmers, but not to the researchers, the problem of endogeneity in adoption behavior can be solved by adopting simultaneous equation models (Alene and Manyong 2007; Hausman 1983).

The other econometric issue involved here, even after accounting for endogeneity, is the sample selection bias. The vital query that remains is whether is it appropriate to use a pooled sample of adopters and non-adopters (where a dummy variable can be used in the regression model to evaluate the impact of adoption of modern technology on productivity)? If the entire sample is selected, it implicitly assumes that technology will have an average impact on productivity over the entire sample of farmers by the way of an intercept shift in the production function. The pooled-sample estimation assumes the same impact of the set of covariates on adopters and non-adopters (Kassie et al. 2007, 2009). This implies that the marginal impact of other conventional factors (land, labor, fertilizer, irrigation, and others) and non-conventional factors (education, extension, experience, and so on) is independent of the status of adoption (Asfaw et al. 2012). But, if we assume that the marginal impact of those factors (slope parameters) is not independent of technology adoption, and they have different impacts on productivity based on technology adoption, then different production functions should be used for adopters and non-adopters separately. Thus, the econometric problems involved here are both endogeneity (Hausman 1978) and sample selection bias (Heckman 1979). This motivates us to use an endogenous switching regression model that takes care of both endogeneity and sample selection problem (Asfaw et al. 2012; Di Falco et al. 2011; Freeman et al. 2001).

\section{Endogenous switching regression}

In endogenous switching regression model, the first stage involves modeling of the adoption behavior with the limited-dependent variable method. In the second stage, another decision variable (productivity) is estimated separately for each group (adopters and non-adopters), conditional on the adoption decision. So, a binary probit model is used in the first stage to model the adoption behavior, and in the second stage, separate regression models are used to model agricultural production function conditional on a specified criterion function.

Following Ali and Abdulai (2010) and Asfaw et al. (2012), the decision to adopt can be modeled in the framework of utility maximization. The difference between the utilities from adoption $\left(U_{\mathrm{Ai}}\right)$ and non-adoption $\left(U_{\mathrm{Ni}}\right)$ of modern varieties $(\mathrm{MVs})$ of 
paddy may be denoted as $G^{*}$, such that the $i^{\text {th }}$ household would like to adopt the given technology if $U_{\mathrm{Ai}}$ is greater than $U_{\mathrm{Ni}}$. In other words, the $i^{\text {th }}$ household will adopt when $G^{*}=U_{\mathrm{Ai}}-U_{\mathrm{Ni}}>0$. But, $G^{*}$ is unobservable. So, we can express it as a function of observable factors in this latent variable model (probit model) as follows:

$$
G_{i}^{*}=\beta X_{i}+u_{i} \text { with } G_{i}=\left\{\begin{array}{c}
1 \text { if } G_{i}^{*}>0 \\
0 \text { if } G_{i}^{*} \leq 0
\end{array}\right.
$$

Where $G$ is the dichotomous variable that takes the value 1 if farmer is an adopter of MVs of paddy and 0 otherwise; $\beta$ is the vector of unknown parameters to be estimated, and $X$ is the vector of explanatory variables comprising farmer, farm, and technologyspecific characteristics; and $u$ is the random error term with 0 mean and variance as $\sigma^{2}$. Maximum likelihood estimation procedure is employed to estimate the vector of probit coefficients $\beta$.

Now, the adoption of technology also affects the farm productivity $(Y)$. Let the farm productivity $(Y)$ be a function of conventional and non-conventional factors then $J_{i}$ is the vector of those exogenous factors. In switching regression method, as farm productivity $(\mathrm{Y})$ is conditional on technology adoption status, we use two separate production functions for adopters and non-adopters as follows:

$$
\begin{aligned}
& Y_{1 i}=\alpha_{1} J_{1 i}+\epsilon_{1 i} \quad \text { if } G_{i}=1 \\
& Y_{0 i}=\alpha_{0} J_{0 i}+\epsilon_{0 i} \text { if } G_{i}=0
\end{aligned}
$$

The variables $Y_{1}$ and $Y_{0}$ are the agricultural productivity (paddy yield) under new technology (MVs) and traditional technology (local), respectively. For a given household, $Y_{1}$ or $Y_{0}$ is observable depending on the values of the criterion function in Eq. (1). Therefore, the ordinary least squares (OLS) estimates of parameter vector $J_{1}$ or $J_{0}$ will be biased as they suffer from sample selection bias. The errors $\epsilon_{1}$ and $\epsilon_{0}$, conditional on sample selection criterion will have non-zero expected values (Lee and Trost 1978; Maddala 1983). Finally, the error terms $u, \epsilon_{1}$, and $\epsilon_{0}$ are assumed to have a trivariate normal distribution with 0 mean and non-singular covariance matrix expressed as follows:

$$
\operatorname{COV}\left(\epsilon_{1 i}, \epsilon_{0 i}, u_{i}\right)=\left(\begin{array}{ccc}
\sigma_{\epsilon 1}^{2} & \sigma_{\epsilon 1 \epsilon 0} & \sigma_{\epsilon 1 u} \\
\sigma_{\epsilon 1 \epsilon 0} & \sigma_{\epsilon 0}^{2} & \sigma_{\epsilon 0 u} \\
\sigma_{\epsilon 1 u} & \sigma_{\epsilon 0 u} & \sigma_{u}^{2}
\end{array}\right)
$$

Where $\sigma_{u}^{2}$ is the variance of the error in the criterion Eq. (1); $\sigma_{\epsilon 1}^{2}$ and $\sigma_{\epsilon 0}^{2}$ are the variance of the errors $\epsilon_{1}$ and $\epsilon_{0}$, respectively, in productivity outcome functions in Eq. (2); and $\sigma_{\epsilon 1 u}$ and $\sigma_{\epsilon 0 u}$ are the covariance of error terms $u, \epsilon_{1}$, and $\epsilon_{0}$. The outcome functions in Eq. (2) are not observed simultaneously. So, the covariance between $\epsilon_{1}$ and $\epsilon_{0}$ is not defined (Maddala 1983). However, a significant inference of the error structure is that as the error $u$ of criterion function is correlated with the error terms of the productivity functions in Eq. (2), the expected values of the error terms are non-zero, conditional on the sample selection, and expressed as:

$$
\begin{aligned}
& E\left[\epsilon_{1 i} \mid \mathrm{G}_{i}=1\right]=\sigma_{\epsilon 1 u} \frac{\phi\left(\beta X_{i} / \sigma\right)}{\Phi\left(\beta X_{i} / \sigma\right)} \equiv \sigma_{\epsilon 1 u} \lambda_{1 i} \\
& E\left[\epsilon_{0 i} \mid \mathrm{G}_{i}=0\right]=-\sigma_{\epsilon 0 u} \frac{\phi\left(\beta X_{i} / \sigma\right)}{1-\Phi\left(\beta X_{i} / \sigma\right)} \equiv \sigma_{\epsilon 0 u} \lambda_{0 i}
\end{aligned}
$$


where $\phi($.$) and \Phi($.$) are the standard normal probability density function and standard$ normal cumulative density function, respectively. $\lambda_{1 i}$ and $\lambda_{0 i}$, i.e., the estimated ratio of $\phi($.$) , and \Phi($.$) evaluated at \beta X_{i}$ is the inverse Mills ratio. If the estimated covariance $\sigma_{\epsilon 1 u}$ and $\sigma_{\epsilon 0 u}$ are statistically significant, it implies that adoption decision and productivity outcome variable are correlated. So, we find the evidence of endogenous switching and reject the null hypothesis of no sample selection bias (Maddala and Nelson 1975).

The full information maximum likelihood (FIML) estimation method is considered to be the most efficient one to estimate the endogenous switching regression model (Asfaw et al. 2012; Di Falco et al. 2011; Lokshin and Sajaia 2004). It estimates simultaneously the criterion equation (probit model) and the productivity outcome functions to give consistent standard errors. On the basis of the trivariate normal distribution for the error terms, the logarithmic likelihood function for the system of Eqs. (1) and (2) can be given as:

$$
\begin{aligned}
\operatorname{Ln} L & =\sum_{i=1}^{N} G_{i}\left[\ln \phi\left(\frac{\epsilon_{1 i}}{\sigma_{\epsilon 1}}\right)-\ln \sigma_{\epsilon 1}+\ln \Phi\left(\phi_{1 i}\right)\right] \\
& +\left(1-G_{i}\right)\left[\ln \phi\left(\frac{\epsilon_{0 i}}{\sigma_{\epsilon 0}}\right)-\ln \sigma_{\epsilon 0}+\ln \left(1-\Phi\left(\phi_{0 i}\right)\right)\right]
\end{aligned}
$$

Where $\phi_{j i}=\frac{\left(\beta X_{i}+\gamma_{j} \epsilon_{i j} / \sigma_{j}\right)}{\sqrt{1-\gamma_{j}^{2}}}, j=0,1$ with $\gamma_{j}$ denoting the correlation coefficient between the error term of criterion function, i.e., $u_{i}$ and the errors of outcome functions, i.e., $\epsilon_{j i}$. The entire system of the equations is jointly estimated by full information likelihood method.

\section{Study area and sampling strategy}

The study is based on the primary data at the household level collected from two districts of Odisha, Cuttack, and Khordha during 2012 to 2013 cropping season. It focused only on the kharif season which is a major paddy-producing season in Odisha. ${ }^{6}$ A multistage purposive sampling method was used to pin down the households surveyed. First, the two districts, Cuttack and Khordha, were selected purposively based on the scale of paddy production and intensity of agricultural research and development (R\&D) activities being carried out. The paddy is a major crop grown in these two districts, and more importantly, two major agricultural research institutes, that is, Central Rice Research Institute (CRRI) and Odisha University of Agriculture and Technology (OUAT), are situated in Cuttack and Khordha district, respectively. Thus, the farmers in these two districts are equally exposed to different $R \& D$ activities in agriculture. However, we hypothesize that the educated farmers will capture the information better than uneducated or less educated farmers. In the next step, two different development blocks are chosen randomly. From each block, three villages were chosen, and from each village, households were surveyed randomly. The total sample included 300 farming households, 152 from Cuttack and 148 from Khordha.

The survey collected information on farmers' specific socioeconomic characteristics along with farm-specific factors. Table 1 shows the construction of all variables, and Table 2 shows the significance of the difference between the mean values of some continuous variables pertaining to adopters and non-adopters of 
Table 1 Definition of variables and hypotheses

\begin{tabular}{|c|c|c|}
\hline Variable & Description & $\begin{array}{l}\text { Hypothesized } \\
\text { sign }\end{array}$ \\
\hline \multicolumn{3}{|c|}{ Dependent variable } \\
\hline ADPN & $\begin{array}{l}\text { Dummy for the adoption of modern varieties of paddy ( } 1 \text { if adopted, } 0 \\
\text { otherwise) }\end{array}$ & \\
\hline YIELD & Paddy yield in kilogram (kg/ha) & \\
\hline \multicolumn{3}{|c|}{ Independent variables } \\
\hline EXP & Farming experience of a farmer (years) & + \\
\hline $\mathrm{EDNH}$ & Farmer's education (years of schooling) & + \\
\hline EDNDMY-1 & $\begin{array}{l}\text { Head's education dummy (EDNDUMMY }=1 \text { if } 5 \text { years or more of schooling, and } \\
0 \text { otherwise) }\end{array}$ & + \\
\hline EDNDMY-2 & $\begin{array}{l}\text { Head's education dummy (EDNDUMMY }=1 \text { if } 10 \text { years or more of schooling, and } \\
0 \text { otherwise) }\end{array}$ & + \\
\hline AVGEDN & $\begin{array}{l}\text { Average education of household (average years of schooling of all household } \\
\text { members) }\end{array}$ & + \\
\hline HS & Household size (numbers) & $?$ \\
\hline ARPDY & Area under paddy cultivation (ha) & + \\
\hline TLC & Total labor cost (rupees/ha) & + \\
\hline SQ & Soil quality on the basis of farmers own assessment ( 1 if fertile, 0 otherwise) & + \\
\hline FRT & Total fertilizer use (kg/ha) & + \\
\hline ECDMY & Ecosystem dummy ( 1 if irrigated ecosystem, 0 if rainfed ecosystem) & + \\
\hline EXTN & Contacts with extension officials ( 1 if yes, 0 if no) & + \\
\hline TNCY & Tenancy structure (proportion of leased-in area to total operated landholding) & $?$ \\
\hline SEED & $\begin{array}{l}\text { Availability of MV seeds to the farmer through barter exchange or purchasing } \\
\text { from the market ( } 1 \text { if exchanged, } 0 \text { if purchased) }\end{array}$ & + \\
\hline CRDIT & Access to credit ( 1 if accessed, 0 if no) & + \\
\hline SOC & $\begin{array}{l}\text { Social capital in the form of developmental group membership ( } 1 \text { if member of } \\
\text { a group, } 0 \text { if no) }\end{array}$ & + \\
\hline MKTD & Distance to the local market (kilometers) & - \\
\hline MEDIA & Access to media ( 1 if he owns television or radio, 0 otherwise) & + \\
\hline LIVSTK & Ownership of livestock (no. of livestock adult equivalent) & + \\
\hline SRTMC & Farmer's perception about short maturity characteristics of MVs ( 1 if yes, 0 if no) & + \\
\hline YLDC & Farmer's perception about higher yield characteristics of MVs ( 1 if yes, 0 if no) & + \\
\hline TASTEC & Farmer's perception about taste characteristic ( 1 if yes, 0 no) & + \\
\hline
\end{tabular}

The hypotheses indicate the hypothetical relationship between the explanatory variables with MVs adoption (dependent variable). The question mark in the hypothesis indicates the existence of an ambiguous theoretical relation between that variable and adoption

Source: author's field survey 2012 to 2013

MVs. ${ }^{7}$ In this study, an adopter is defined as one who cultivates any type of modern varieties of paddy, ${ }^{8}$ no matter how much land of total holding is being devoted to the adoption of MVs of paddy. Some adopters were found to allocate some land for traditional varieties (TVs) of paddy also.

\section{Variables and estimation strategy}

The adoption decision is a dichotomous one. The dependent variable (ADOPTION) takes the value 1 if the farmer adopts the MVs of paddy and 0 otherwise. The probit model is used to estimate the adoption behavior (criterion equation). 
Table 2 Descriptive statistics and mean differences of continuous variables

\begin{tabular}{|c|c|c|c|c|}
\hline \multirow[t]{2}{*}{ Variable } & \multicolumn{3}{|l|}{ Mean values } & \multirow[b]{2}{*}{ t statistic } \\
\hline & Adopters & Non-adopters & Total sample & \\
\hline Paddy yield (YIELD) & $2896.74(818)$ & $2000.80(637)$ & $0.640(0.674)$ & $2.471^{* * *}$ \\
\hline Area under paddy (ARPD) & $1.033(0.684)$ & $0.378(0.397)$ & $0.629(0.538)$ & $14.865^{* * *}$ \\
\hline Farming experience (EXP) & $21.63(8.487)$ & $23.57(8.232)$ & $22.02(8.317)$ & -0.841 \\
\hline Farmer education (EDNH) & $5.421(2.711)$ & $2.882(2.990)$ & $3.014(2.348)$ & $14.824^{* * *}$ \\
\hline Average education (AVGEDN) & $7.868(2.393)$ & $6.091(2.019)$ & $7.00(2.227)$ & $6.862^{* * *}$ \\
\hline Household size (HS) & $6.527(1.921)$ & $6.601(1.682)$ & $6.561(1.804)$ & -0.361 \\
\hline Total labor cost (TLC) & 20,666 (21279) & $10,043(7410)$ & $15,744(16387)$ & $5.598^{* * *}$ \\
\hline Fertilizer used (FRTR) & $68.72(31.32)$ & $32.42(31.33)$ & $55.21(34.47)$ & $8.321^{* * *}$ \\
\hline Tenancy structure (TNCY) & $0.032(0.078)$ & $0.067(0.097)$ & $0.048(0.087)$ & $-3.523^{* * *}$ \\
\hline Distance to market (MKTD) & $2.516(1.148)$ & $2.439(1.074)$ & $2.451(1.119)$ & 0.742 \\
\hline Livestock (LIVSTK) & $7.432(3.666)$ & $2.553(1.508)$ & $4.942(2.790)$ & $15.145^{* * *}$ \\
\hline
\end{tabular}

The figures within the brackets are standard deviations corresponding to the mean values of the respective variables. The difference between the mean values of all continuous variables pertaining to adopters and non-adopters is tested under the assumption of equal variances ${ }^{* * *}$ and ${ }^{* *}$ indicate significance at $1 \%$ and $5 \%$ level, respectively) Source: author's field survey 2012 to 2013

$$
\begin{aligned}
& \operatorname{Pr}(\mathrm{ADOPTION}=1)=f(\mathrm{EXP}, \mathrm{EDN}, \mathrm{ECDMY}, \mathrm{HS}, \mathrm{ARPDY}, \mathrm{SQ}, \\
& \text { EXTN, TNCY, CRDIT, MKTD, SOC, MEDIA, LIVSTCK, SRTMC, TASTEC })
\end{aligned}
$$

The independent variables are farm-specific and other institutional factors. Farmerspecific variables are farming experience in years (EXP), farmer's education (EDN), and his household size (HS) in numbers. Educational status variable (EDN) is defined differently by using different specifications as (i) first, years of schooling of household head; (ii) second, the average years of education of the household; and (iii) third, two dummy variables defined as 5 years of schooling or more and 10 years of schooling or more. The first dummy variable takes the value 1 if the head's education is of 5 years of schooling or more and 0 otherwise. The second dummy variable takes the value 1 if it is 10 years of schooling or more and 0 otherwise. ${ }^{9}$ The reason for taking 5 and 10 years of schooling spawns from the argument that in a basic education cycle, 5 years of schooling is considered as minimum education level as it completes primary education, and 10 years of schooling completes the secondary level of education or high school education in India. ${ }^{10}$ All these specifications of education (EDN) variable are hypothesized to have positive impact on adoption. There is a significant mean difference in the level of education between adopters and non-adopters. The farm-specific factors include total paddy area (ARPDY) in hectare, soil quality (SQ), and total cost of hired labour (TLC) in thousand rupees and ecosystem dummy (ECDMY). We hypothesized a positive relation between these farm-specific factors and adoption. The mean values of total paddy area (ARPDY) vary significantly in-between adopters and non-adopters of MVs. The set of institutional variables includes social capital (SOC), tenancy structure (TNCY), access to credit (CRDIT), extension visits dummy (EXTN), ownership of livestock (LIVSTCK), distance to market (MKTD), and access to media dummy (MEDIA). The tenancy structure is constructed as the proportion of leased-in operated area in total operational landholding. In our study region, generally, some farmers leased in some lands from other relatively big farmers who are either staying away from villages or not doing cultivation since their main source of livelihood is non-farm activities. So, 
this is not sharecropping where a farmer allies with another farmer. Similarly, we have constructed the dummy variable "MEDIA" as the one that takes value 1 if a farmer owns a television and 0 otherwise. In the existing literature, many studies have taken a radio or both radio and television. But, intuition tells that audiovisual source of information is more effective than only audio. The set of technology characteristic-related variables includes farmer's perception about the maturity period of the crop (MATC), higher productivity characteristic (PRDTYC), and the availability of seeds at a cheaper price (CHEPSC). All these technology characteristics related variables are dummy variables taking the value 1 if the farmer perceives so about the MVs and 0 if not.

In order to estimate the yield equations (outcome function) for the adopters as well as non-adopters separately on the basis of criterion equation, the following functional form of the equations is specified here as:

$$
\begin{aligned}
& \operatorname{Ln}(\mathrm{YIELD})_{j}=\alpha_{0 j}+\alpha_{1 j}(\mathrm{ECDMY})_{j}+\alpha_{2 j} \operatorname{Ln}(\mathrm{ARPDY})_{j}+\alpha_{3 j}(\mathrm{EDN})_{j}+ \\
& \alpha_{4 j}(\mathrm{EXTN})_{j}+\alpha_{5 j} \operatorname{Ln}(\mathrm{FERT})_{j}+\alpha_{6 j}(\mathrm{SQ})_{j}+\alpha_{7 j} \operatorname{Ln}(\mathrm{TLC})_{j}+\varepsilon_{j} ; \quad j=0,1
\end{aligned}
$$

The dependent variable $\operatorname{Ln}($ YIELD) is natural logarithm of paddy yield expressed as kilogram per hectare. ${ }^{11}$ There is a significant mean difference of yield in-between adopters and non-adopters of MVs. The set of conventional and non-conventional factors included here in the outcome equation are education, extension, total area under paddy, ecosystem dummy, total fertilizer use, total labor cost, and soil quality. There is a significant mean difference between adopters and non-adopters in the case of labor cost and total fertilizer use. All these conventional and non-conventional factors of production are hypothesized to have yield-augmenting effects. However, it is hypothesized that formal education (EDN) will have a differential impact on agricultural productivity under modern and traditional technologies.

Following Asfaw et al. (2012), Di Falco et al. (2011), and Maddala (1983), the three technology characteristic variables along with some others are not included in yield equations on the basis of the assumption that these variables are not likely to influence paddy production directly. Rather, they influence through technology adoption. Thus, the usual order condition for identification purpose is followed so that the $X_{i}$ in the adoption equation (criterion equation) contains at least one factor not in $J_{i}$ in the yield equation (outcome equation). The FIML method is employed to estimate the system of equations jointly.

\section{Results and discussion}

\section{Determinants of modern varieties of paddy adoption}

Table 3 gives the results of the first stage estimation of endogenous switching regression model for various factors affecting adoption of modern varieties of paddy (criterion equation). Different specifications were tried on the basis of various measures of education variable. All the model specifications fit well to the data set as indicated by the likelihood ratio test that the coefficient parameters are statistically significantly different from 0 at $1 \%$ significance level and the pseudo R-squared value is quite high. Four different measures for education variable, i.e., years of schooling of the farmer, two dummy variables for head's education, and the average years of schooling of the household, were incorporated in the analysis. ${ }^{12}$ The four measures were incorporated in four model specifications. The measure of an average year of schooling in the fourth 


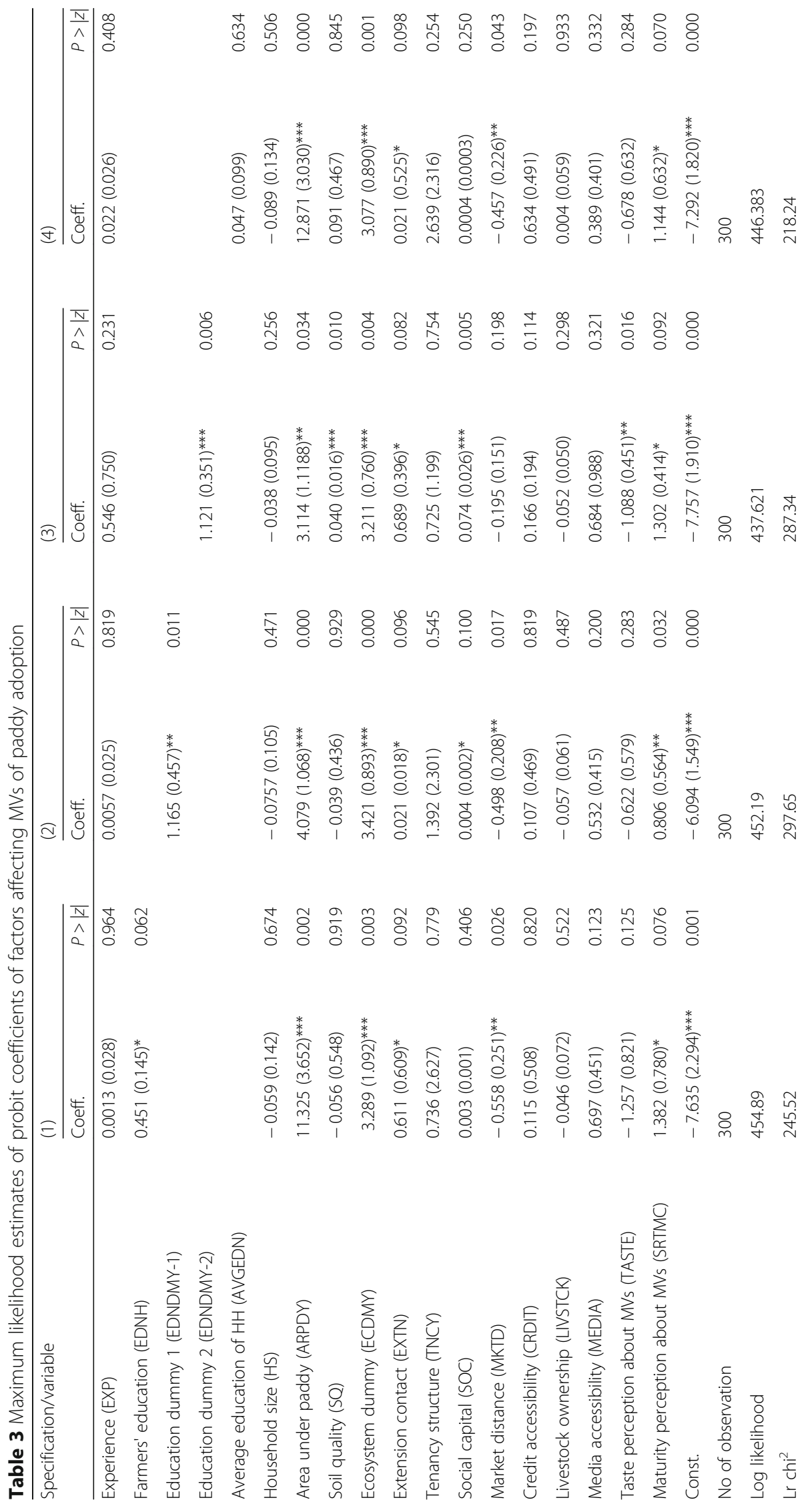




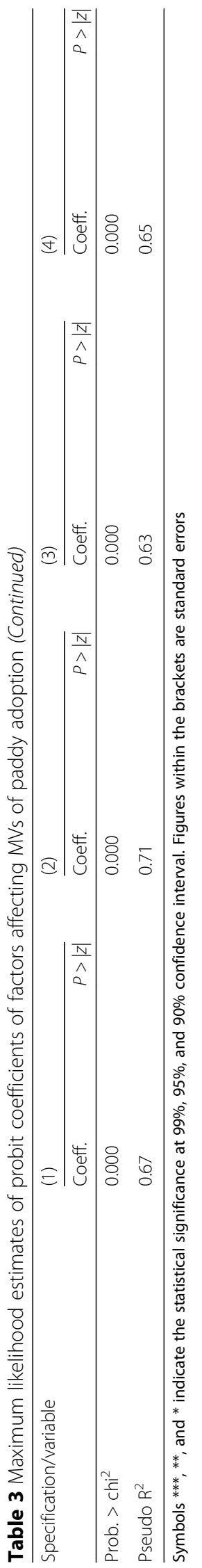


model specification did not come out significant. But, the other three measures are statistically significant. The variable "years of schooling of the farmers" is significant at $10 \%$ probability level while both education dummy variables (EDNDMY) as defined earlier are significant at $5 \%$ and $1 \%$ probability levels, respectively. So, this confirms our hypothesis that education has a strong threshold effect on the probability of adoption of modern technology. This result is supported by many studies like Alene and Manyong (2007) and Phillips (1994). Farming experience (EXP) is positive but insignificant. The household size (HS) is negative though insignificant. The hypothetical relation was assumed to be positive. But, empirical evidence shows the reverse relation. The reason may be that big family spends more on consumption durables and developmental activities rather than modernization of agriculture. Other significant variables are total paddy area (ARPDY), ecosystem dummy (ECDMY), contact with agricultural extension service (EXTN), social capital (SOC), distance to local market (MKTD), and one technology characteristic variables, i.e., short maturity of MVs (SRTMC). The adoption of new technology is usually initiated by the large farmers as they can withstand both subjective and objective risks attached with modern technology. Therefore, as the total paddy area (ARPDY) increases, there is a better prospect for adoption. Ecosystem dummy is highly significant indicating thereby that if the farmers have irrigated land, then they are more likely to adopt modern technology. Contact with agricultural extension services lends a great deal of help to the farmers. The farmers learn more about the new technology from the extension service officers. So, farmers who frequently visit the extension office and keep regular contact with them are usually more progressive and quickly adopt the new technology. Thus, it was hypothesized to be positive, and we found results in line with that theoretical hypothesis. Soil quality retains its positive sign but insignificant. Though, a fertile soil is quite an important factor making a conducive environment for adoption of MVs of paddy but, it does not affect the adoption behavior significantly here in the study region because a major portion of the farmland belongs to the same quality of soil fertility. So, it does not make a big difference. Social capital in the form of membership of developmental groups influences the probability of adoption significantly. It breaks the barrier of information asymmetry and helps in the cross-fertilization of ideas. The existence of local market acts as an information hub to the farmers. If the distance to local market is more, then farmers are less likely to get the information about new farm practices. So, it hampers technology adoption. We get significant and negative results as expected. Out of two technology characteristics, only farmer's perception about the short maturity period of MVs is significant.

\section{Determinants of agricultural productivity}

Table 4 presents the results of the second stage of endogenous switching regression model. We estimated four different specifications of the outcome equation (yield equation) corresponding to each specification of criterion equation on the basis of various measures of education variable. The correlation coefficients between the error of criterion equation (adoption) and errors of outcome equations (yield equations) in each specification are given in the last row. The estimated correlation coefficients in all four specifications are significant indicating that both observed and unobserved factors are influencing the decision to adopt. Thus, the results of the adoption model and 


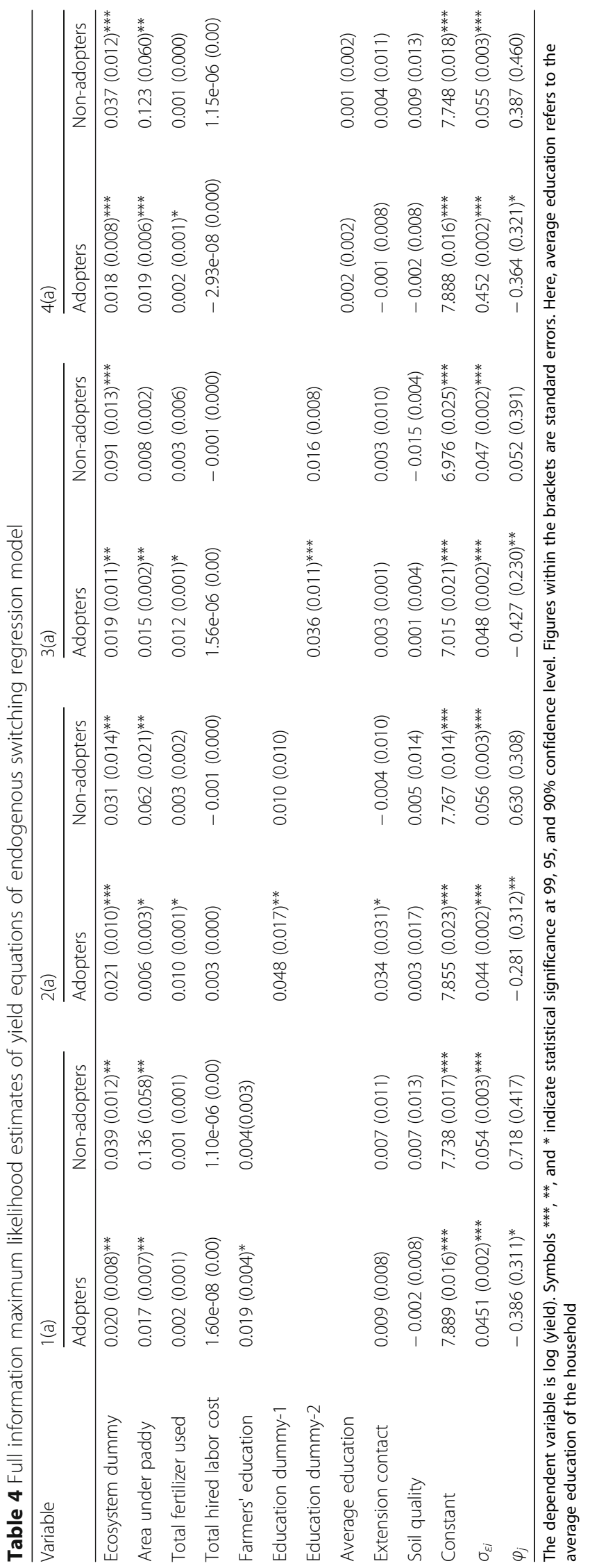


switching regression model together suggest the existence of endogeneity and the problem of self-selection. In other words, the decision to adopt and the impact of technology on yield given the adoption decision, are influenced by both observed and unobserved factors. The alternative signs of both correlation coefficients suggest that adopters adopt modern varieties on the basis of their comparative advantages. In other words, those who adopted have above-average returns from adoption, and those who did not choose to adopt have above-average returns from non-adoption (Alene and Manyong 2007; Fuglie and Bosch 1995). The insignificance of the correlation coefficient between adoption equation and non-adopters' yield function in all four specifications indicates that adopters and non-adopters obtain the same mean yield of paddy using local varieties, given their observed characteristics. Thus, the initial difference between the adopters and non-adopters is insignificant, but the differential effects of technology on the two groups are brought by some unobserved factors.

The switching regression results in Table 4 demonstrate that majority of the conventional factors of production have expected signs. But, the marginal effects are different in the case of both adopters and non-adopters confirming the differential marginal impacts of factors on paddy yield between adopters and non-adopters. The ecosystem dummy is significant in the case of both modern and traditional paddy varieties. This reveals that overall paddy yield is positively and significantly influenced by assured irrigation being represented by ecosystem dummy (ECDMY), no matter whether it is modern varieties or traditional varieties. Of course, paddy is water-intensive crop and it consumes plenty of water. So, assured irrigation is a must for paddy cultivation. Similarly, the total area under paddy (ARPDY) is also positively and significantly influencing paddy yields in the case of both MVs and TVs of paddy. Bigger farm size brings many economies of scale in farm production process. Optimal use of many farm inputs can be achieved if the size of holding is a big one. So, bigger farm size is always hypothesized to have a positive impact on productivity. Total fertilizer used (FERT) was being hypothesized to have yield augmenting effects in the case of both varieties, and it retains its expected sign. But, it is significant only in the case of modern varieties. In fact, both fertilizer and MVs are complementary to each other, and both were introduced to Indian farmers as a package during the 1960s that marked the onset of green revolution in Indian agriculture (Bezbaruah 1994). Even, the output elasticity of fertilizer is bigger in the case of MVs of paddy in comparison to TVs. However, soil quality (SQ) is positive but insignificantly affecting farm production under both technologies. Contact with agricultural extension services is only significant in the second and third specification in the case of adopters only. So it is not that much of an influential factor here.

The main objective of this study is to analyze the impact of education on paddy yield in the case of MVs and TVs to test the Schultz hypothesis. The average years of schooling of the household did not reveal any significant effects on paddy yield in the case of both adopters and non-adopters (specification 4(a)). This is consistent with other Indian studies such as Narayanamoorthy (2000) who also concluded the same insignificant effects of average years of schooling of households on paddy yields. Lack of significant influence of average education implies the absence of centralized decision-making in farming as evidenced by Asadullah and Rahman (2009) and Mussa (2015). It is because of the reason that distribution of landholding in Odisha is severely skewed towards marginal farmers $(77.17 \%$ out of total number of farmers) and small farmers (20\%) with the average size of holding in the 
state being 1.04 ha as per 2010 to 2011 census (Odisha Agriculture Statistics 2013-2014). In our sample also, most of the farmers belong to these two categories. Therefore, in a subsistence agriculture, the decision-making solely rests with the farmer himself. The other educated members of the household prefer other non-farm activities rather than being engaged in agriculture. However, as expected, the other three measures of education variable, that is, years of schooling of the head and both dummy variables, revealed a significant impact on paddy yield in the case of adopters only. Again, the level of statistical significance of education dummies is higher than the years of schooling (specification 1(a), 2(a), and 3(a) of Table 4). The second dummy variable having the threshold level as 10 years of schooling is significant at $1 \%$ probability level in comparison to other two measures. Thus, this indicates that farmer education affects farm productivity significantly under modern technology, and it has a strong threshold effect on farm productivity. This result is supported by many studies like Alene and Manyong (2007), Asfaw et al. (2012), Lockheed et al. (1980), and Phillips (1994). ${ }^{13}$ Thus, the farmers who completed minimum education of secondary level are most likely to adopt MVs and experience the yield augmenting effects of education. This indicates that attaining a minimum threshold level of education helps farmers in ways of enhancing their skills and capabilities to collect and analyze the information and execute that on the field. It creates a conducive environment to go for modern technology adoption and thereby augments the productivity. Unless that minimum basic education is attained, formal education does not influence productivity. The results clearly demonstrate that coefficients of the two measures of education are positive in the case of both adopters and nonadopters but significant only in the case of adopters. Even, the differential impact is also noticed in-between the two paddy varieties. The output elasticities of education in the case of adopters of modern varieties are $0.019,0.048$, and 0.036 , respectively, in the first three model specifications while they are $0.004,0.010$, and 0.016 for non-adopters, respectively. Hence, the results support Schultz's argument that formal education has a significant marginal contribution to farm production only under modern technology. This result is consistent with the earlier studies like Asfaw et al. (2012), Alene and Manyong (2007), Lockheed et al. (1980), Phillips (1994), and others. The reason for this as argued by Schultz (1964) is that farmers in the traditional environment are already efficient. Thus, educational efforts offer little or no marginal contribution to production (cited in Alene and Manyong 2007, p. 156). But, the modern mode of production requires the formal education which may not be necessary for traditional agriculture. So, we are likely to get confounding results if we fail to take into account the technology differences available to farmers even in the same farming environment.

\section{Conclusion}

We view our study as fulfilling a couple of important research gaps in the literature. First, the method used in this study is an improvement over the methods used in the past literature. Many earlier studies understated the true marginal contribution of education to agricultural productivity by adopting an OLS method of estimation of the single production function. Because the OLS method of estimation of the single production function for all farmers does not take into account the heterogeneity that exists among the farmers so far as technology adoption is concerned. Even if a dummy variable is incorporated in the OLS model to account for technology adoption, it falls into the trap of endogeneity problem as technology adoption is highly endogenous. But, in this study, the endogenous switching 
regression model is used which is free from endogeneity and sample selection bias. So, the results are unbiased and robust. Second, the use of years of schooling of the head or average years of schooling of the household as the education variable in regression model acts as the major source of confounding results. Because these two variables do not reveal any strong significant effect on productivity as there is a strong threshold effect of education on farm productivity. Even in this study, we also got insignificant influence of average years of schooling of household and very low level of significance for years of schooling of the farmer. But, both education dummies defined as 5 years of schooling or more and 10 years of schooling or more revealed highly significant impact of education on agricultural productivity. Third, the results of endogenous switching regression model confirmed that formal education has a differential impact on farm productivity of adopters and non-adopters of modern technology, even in the same physical environment that they all operate in together. Thus, it supports the Schultz's hypothesis that in the modernized agriculture, education does play a significant role.

The effects of education will be much more if suitable policies are implemented properly. As evidenced from the analysis, education has a strong threshold effect in the successful adoption of MVs of paddy and thereby paves the way for achieving better yields. Farmer education is complementary to the research and development activities that take place in the farm sector because the application of scientific knowledge for agricultural development becomes a major concern when the human resources involved in it are unskilled and incompetent due to mass illiteracy. Therefore, educating farmers about the application of various modern technologies needs to be emphasized. The implementation of farmer field school (FFS) program along with strong extension service could help in this direction as it is an innovative, participatory, and interactive model approach to educate the farmer about various farm practices, crop management strategies, and technological up-gradation.

\section{Endnotes}

${ }^{1}$ Lockheed et al. (1980) and Phillips (1994) surveyed some early studies conducted worldwide while Tilak (1993) surveyed some studies conducted in Asia, and Appleton and Balihuta (1996) surveyed comprehensively on the same issue in the case of African countries only.

${ }^{2}$ The dummy variable shows threshold level of education where the threshold is mostly taken as 4 years of schooling. It has been argued that the 4 years of schooling constitute the minimum level in the basic education cycle (Lockheed et al. 1980). However, some studies have taken different thresholds, for instance, Jamison and Moock (1984) have taken 6 years or more. Recent studies like Narayanamoorthy (2000) and Asadullah and Rahman (2009) have taken the dummy of 5 years of farmer education as minimum threshold. But, Narayanamoorthy did not include that variable in regression analysis.

${ }^{3}$ Lockheed et al. (1980) and Phillips (1994) discussed the issue of 'whose education matters' and surveyed many studies in detail in this regard. Recently, Mussa (2015) has taken average years of schooling of household and maximum and minimum years of schooling any member of household in his analysis.

${ }^{4}$ Kalirajan and Shand (1985) in their study argued that in technologically advanced area, where there are no serious production constraints like input unavailability, extension service, schooling of farmer is not necessarily a major factor of efficient 
production performance. Rather, they argued that no difference exists between educated farmers and illiterate farmers if the technology is communicated properly. Thus, understanding of the technology is more important than the formal education.

${ }^{5}$ Duraisamy (1992) used both years of schooling of the farmer and average education of the household and some dummy variable. He found all the variables significantly and positively influencing crop yield. But the issues of differences in farming environments and technologies available to the farmers are not taken into consideration.

${ }^{6}$ In Odisha, paddy is cultivated in three different cropping seasons, that is, kharif season (June to September), rabi season (October to February), and the summer season (March to May). However, the kharif season is the major rice-producing season that accounts for $94 \%$ of total rice area and 92\% of total rice production (Odisha Agriculture Statistics 2013-2014).

${ }^{7}$ The $t$ statistic used here to demonstrate the mean difference between adopters and non-adopters is computed as: $t=\left(y_{\mathrm{A}}-y_{\mathrm{N}}\right) / \sqrt{\operatorname{Var}\left(y_{\mathrm{A}}\right) / n_{\mathrm{A}}+\operatorname{Var}\left(y_{\mathrm{N}}\right) / n_{\mathrm{N}}}$, where $n_{\mathrm{A}}$ and $n_{\mathrm{N}}$ are the number of adopters and non-adopters of MVs, respectively, and $y_{\mathrm{A}}$ and $y_{\mathrm{N}}$ are the sample means of a respective variable for adopters and non-adopters. The degree of freedom is $n_{\mathrm{A}}+n_{\mathrm{N}}-2$.

${ }^{8}$ Modern varieties of paddy include the new generation of high yielding varieties (HYV) as well as hybrid seeds and recently developed stress tolerant varieties. Details can be found in Paltasingh (2014). Though, a farmer is considered as an adopter irrespective of the amount of land being devoted to adoption of MVs. However, observation shows that majority of farmers who adopt MVs devote a major portion of their landholding to MVs adoption.

${ }^{9}$ Many studies have taken different thresholds. For details, see Lockheed et al. (1980), Phillips (1994), and Tilak (1993).

${ }^{10}$ In India, education up to 10th class is considered as secondary level which comes under the "Board of Secondary Education," and 11th and 12th classes are considered as higher secondary education which comes under "Council of Higher Secondary Education." This system is uniform broadly across the states. Therefore, 10 years of schooling marks the completion of the secondary level of education.

${ }^{11}$ The dependent variable in the outcome function is overall paddy yield. In fact, there are some farmers who adopt both varieties, and when we take yield in outcome function for adopters, it is the overall yield of adopters, no matter whether he is a complete adopter or partial adopter.

${ }^{12}$ Some other specifications of education variable like proportion of other members who completed primary education, spouse's education, and the highest level of education of any member of the household are also tried, but all of them are found to be insignificant. So they are not reported here.

${ }^{13}$ First two studies have taken dummy of 4 years of schooling while the last study tried different thresholds. However, many other studies have taken dummy variable indicating a threshold level of education. Details can be found in Lockheed et al. (1980) and Phillips (1994). 
Authors' contributions

KRP acquired the data and contributed in the development of the model, drafting the article, and analysis of the results. PG revised the paper critically for important intellectual content and rechecked the results. Both authors read and approved the final manuscript.

\section{Authors' information}

KRP is an assistant professor in the School of Economics, SMVD University, India. PG is a professor in the School of Economics, University of Hyderabad, India.

\section{Competing interests}

Both authors declare that they have no competing interests.

\section{Publisher's Note}

Springer Nature remains neutral with regard to jurisdictional claims in published maps and institutional affiliations.

\section{Author details}

${ }^{1}$ School of Economics, SMVD University, Jammu 182 320, India. ${ }^{2}$ School of Economics, University of Hyderabad, Hyderabad 500 046, India.

Received: 31 March 2017 Accepted: 14 February 2018

Published online: 02 May 2018

\section{References}

Abdulai A, Huffman W (2014) The adoption and impact of soil and water conservation technology: an endogenous switching regression application. Land Econ 90(1):26-43

Alene AD, Manyong VM (2007) The effect of education on agricultural productivity under traditional and improved technology in northern Nigeria: an endogenous switching regression analysis. Empir Econ 32(1):141-159

Ali A, Abdulai A (2010) The adoption of genetically modified cotton and poverty reduction in Pakistan. J Agr Econ 61(1):175-192

Ali M, Byerlee D (1991) Economic efficiency of small farmers in a changing world: a survey of recent evidence. J Int Dev $3(1): 1-27$

Appleton S, Balihuta A (1996) Education and agricultural productivity: evidence from Uganda. J Int Dev 8(3):415-444 Asadullah MN, Rahman S (2009) Farm productivity and efficiency in rural Bangladesh: the role of education revisited. Appl Econ 41(1):17-33

Asfaw A, Admassie A (2004) The role of education on the adoption of chemical fertilizer under different socioeconomic environments in Ethiopia. Agric Econ 30(3):215-228

Asfaw S, Shiferaw B, Simtowe F, Lipper L (2012) Impact of modern agricultural technologies on smallholder welfare: evidence from Tanzania and Ethiopia. Food Policy 37(3):283-295

Azhar RA (1991) Education and technical efficiency during the green revolution in Pakistan. Econ Dev Cult Change 39(3):651-665

Battese GE, Coelli TJ (1995) A model for technical inefficiency effects in a stochastic frontier production function for panel data. Empir Econ 20(2):325-332

Bezbaruah MP (1994) Technological transformation of agriculture: a study from Assam. Mittal Publications, New Delhi Chaudhri DP (1979) Education, innovations and agricultural development. Croom Helm, London

Coelli T, Rahman S, Thirtle C (2002) Technical, allocative, cost and scale efficiencies in Bangladesh rice cultivation: a non-parametric approach. J Agr Econ 53(3):607-626

Deb UK (1995) Human capital and agricultural growth in Bangladesh. Dissertation, University of the Philippines, Philippines

Di Falco S, Veronesi M, Yesuf M (2011) Does adaptation to climate change provide food security? A micro-perspective from Ethiopia. Am J Agr Econ 93(3):829-846

Duraisamy P (1992) Effects of education and extension contacts on agricultural production. Ind J Agr Econ 47(2): 205-214

Freeman HA, van der Merwe PJA et al (2001) Assessing the adoption potential of new groundnut varieties in Malawi. Working paper 11. ICRISAT, Patancheru

Fuglie KO, Bosch DJ (1995) Economic and environmental implications of soil nitrogen testing: a switching regression analysis. Am J Agr Econ 77(4):891-900

Haller TE (1972) Education and rural development in Colombia. Dissertation, Purdue University, Indiana

Hasnah EF, Coelli T (2004) Assessing the performance of a nucleus estate and smallholder scheme for oil palm production in West Sumatra: a stochastic frontier analysis. Agric Syst 79(1):17-30

Hausman JA (1978) Specification tests in econometrics. Econometrica 46(6):1251-1272

Hausman JA (1983) Specification and estimation of simultaneous equation models. In: Griliches Z, Intriligator MD (eds) Handbook of econometrics, vol I. North Holland Press, Amsterdam

Heckman J (1979) Sample selection bias as a specification error. Econometrica 47(1):153-161

Hojo M (2004) Measuring education levels of farmers: evidence from innovation adoption in Bangladesh. Discussion Paper 04-06, Osaka University, Japan

Huang F, Luh Y (2009) The economic value of education in agricultural production: a switching regression analysis of selected East-Asian countries. A paper presented in International Association of Agricultural Economists Conference, 16-22 August, Beijing

Jamison DT, Lau L (1982) Farmer education and farm efficiency. Johns Hopkins University Press, Baltimore 
Jamison DT, Moock PR (1984) Farmer education and farm efficiency in Nepal: the role of schooling, extension services and cognitive skills. World Dev 12(1):67-86

Kalirajan KP, Shand RT (1985) Types of education and agricultural productivity: a quantitative analysis of Tamil Nadu rice farming. J Dev Stud 21(2):232-243

Kassie M, Pender J et al (2007) Impact of soil conservation on crop production in the northern Ethiopian highlands. IFPRI Discussion Paper 00733, International Food Policy Research Institute, Washington, D. C

Kassie M, Zikhali P, Pender J, Kohlin G (2009) Sustainable agricultural practices and agricultural productivity in Ethiopia: does agroecology matter? EfD Discussion paper 09-12, Environment for the Development Initiative (EfD)/Resources for the Future (RfF), Washington, D.C

Khonje M, Manda J, Alene AD, Kassie M (2015) Analysis of adoption and impacts of improved maize varieties in eastern Zambia. World Dev 66:695-706

Lee LF, Trost RP (1978) Estimation of some limited dependent variable models with application to housing demand. J Econometrics 8(3):357-382

Llewellyn RV, Williams JR (1996) Nonparametric analysis of technical, pure technical, and scale efficiencies for food crop production in East Java, Indonesia. Agric Econ 15(2):113-126

Lockheed ME, Jamison DT, Lau $\sqcup$ (1980) Farmer education and farm efficiency: a survey. Econ Dev Cult Change 29(1):37-76

Lokshin M, Sajaia Z (2004) Maximum likelihood estimation of endogenous switching regression models. The Stata J 4(3):282-289

Maddala GS (1983) Limited dependent and qualitative variables in econometrics. Cambridge University Press, UK

Maddala GS, Nelson FD (1975) Switching regression models with exogenous and endogenous switching. In Proceeding of the American Statistical Association (Business and Economics Section), pp. 423-426

Mellor JW (1976) The new economics of growth. Cornell University Press, New York

Moock PR (1973) Managerial ability in small farm production: an analysis of maize yields in the Vihiga division of Kenya. Dissertation, Columbia University, USA

Moock PR (1981) Education and technical efficiency in small-farm production. Econ Dev Cult Change 29(4):723-739

Mussa R (2015) The effects of educational externalities on maize production in rural Malawi. Oxford Dev Stud:1-25. https://doi.org/10.1080/13600818.2015.1046826

Narayanamoorthy A (2000) Farmers' education and productivity of crops: a new approach. Ind J Agr Econ 55(3):511-519

Odisha Agriculture Statistics (2013-2014) Directorate of agriculture and food production, Government of Odisha, Bhubaneswar

Paltasingh KR (2014) Technology adoption and climatic risks in agriculture: a study of Odisha. Dissertation, University of Hyderabad, India

Phillips JM (1994) Farmer education and farmer efficiency: a meta-analysis. Econ Dev Cult Change 43(1):149-165

Pudasaini SP (1983) The effects of education in agriculture: evidence from Nepal. Am J Agr Econ 65(3):509-515

Rahman KM, Mia MA et al (2012) A stochastic frontier approach to technical efficiency of rice farmers in Bangladesh: an empirical analysis. Agriculturalists 10(2):9-19

Ram R (1980) Role of education in production: a slightly new approach. Q J Econ 95(2):365-373

Reimers M, Klasen S (2013) Revisiting the role of education for agricultural productivity. Am J Agr Econ 95(1):131-152

Schultz TW (1964) Transforming traditional agriculture. Yale University Press, New Haven

Schultz TW (1975) The value of the ability to deal with disequilibria. J Econ Lit 13(3):827-896

Sharma SR (1974) Technical efficiency in traditional agriculture: an econometric analysis of the Rupandehi district of Nepal. Dissertation, Australian National University, Australia

Singh B (1974) Impact of education on farm production. Econ Polit Weekly 9(39):A92-A96

Tilak JBG (1993) Education and agricultural productivity in Asia: a review. Ind J Agr Econ 48(2):187-200

Wadud A, White B (2000) Farm household efficiency in Bangladesh: a comparison of stochastic frontier and DEA methods. Appl Econ 32(13):1665-1673

Weir S (1999) The effects of education on farmer productivity in rural Ethiopia. Centre for the Study of African Economies Working Paper no. WPS/99-7, Oxford University, Oxford

Young D, Deng H (1999) The effects of education in early-stage agriculture: some evidence from China. Appl Econ 31(11):1315-1323

\section{Submit your manuscript to a SpringerOpen ${ }^{\circ}$ journal and benefit from:}

- Convenient online submission

- Rigorous peer review

Open access: articles freely available online

- High visibility within the field

- Retaining the copyright to your article

Submit your next manuscript at $\gg$ springeropen.com 